\title{
Consequences of pond management for chironomid assemblages and diversity in English farmland ponds
}

\author{
Leslie P. RUSE,${ }^{1 *}$ Helen M. GREAVES,${ }^{2}$ Carl D. SAYER,${ }^{2}$ Jan C. AXMACHAR ${ }^{2}$ \\ ${ }^{1}$ Centre for Research in Ecology, University of Roehampton, London and APEM Ltd., Works Road, Letchworth, SG6 1LW; ${ }^{2}$ Pond \\ Restoration Research Group, Environmental Change Research Centre, Department of Geography, University College London, Gower \\ Street, London, WC1E 6BT, UK \\ *Corresponding author: les.ruse@roehampton.ac.uk
}

\begin{abstract}
Ponds represent a large potential resource for biodiversity in agricultural areas of lowland Europe though many are lost through natural succession towards damp woodland depressions (terrestrialisation). Managing ponds back towards their former open-water state may result in dramatic increases of biodiversity, even on heavily farmed land. Here, evidence is presented of the effects of terrestrialised farmland pond restoration on chironomid assemblages. Chironomid pupal exuviae were collected from three terrestrialised ponds on intensively-farmed land in North Norfolk, Eastern England. Two of the ponds had trees, scrub and sediment removed, while the third pond remained undisturbed as a control. Pupal exuviae collection resumed after the restoration period. In addition, nine unmanaged farm ponds and two formerly restored ponds were sampled. Nearby, another five restored ponds were also sampled for chironomid pupal exuviae. Water data revealed alkalinity, conductivity and phosphorus decreased while $\mathrm{pH}$ and dissolved oxygen increased after pond restoration. Chironomid species diversity, similarity and species compositional change were compared pre- and post-restoration. Assessments were made of chironomid species associated with colonisation of restored ponds as well as ponds without such management. After scrub and sediment removal the earliest colonisation of the ponds was by mudeating species with rapid colonisation traits such as parthenogenesis, multiple generations in one year and tolerance of low oxygen conditions. Subsequent plant growth due to the opening up of the canopy led to consequent improved oxygenation and habitat structure. Other chironomid species dependent on these conditions were then able to compete with the early colonisers. Restoration also made a significant improvement in the number of chironomid species, as assessed by rarefaction curves
\end{abstract}

Key words: Pond restoration; Chironomidae; pupal exuviae; farmland; biodiversity.

Received: February 2018. Accepted: October 2018.

This paper was presented at the $20^{\text {th }}$ International Symposium on Chironomidae, Trento, Italy, 2-8 July 2017.

Session: Ecology and Biomonitoring.

\section{INTRODUCTION}

Ponds represent a major potential resource for biodiversity conservation in agricultural areas of lowland Europe (Ruggiero et al., 2008; Gioria et al., 2010). In UK farmland, agricultural intensification and modernisation since the 1950s have degraded ponds either by being filled in (Wood et al., 2003; Alderton et al., 2017) or through the abandonment of traditional pond management practices, rendering them highly terrestrialised. Highly overgrown ponds, resembling small in-field patches of wet woodland, are overwhelmingly dominant in lowland England leading to low landscape-scale habitat heterogeneity. Comparisons of overgrown ponds with ponds currently managed by traditional means (tree, scrub and occasional mud removal) show significantly higher biodiversity in managed ponds for invertebrates and macrophytes (Sayer et al., 2012, 2013) and also for farmland birds (Davies et al., 2016). Benefits for invertebrates are likely to stem from the presence of abundant and structurally complex macrophyte communities in managed open-canopy ponds and also benefit birds via enhanced invertebrate food-sources.

Previous studies of pond management consequences for aquatic biodiversity and species assembly have focused on cross-comparisons of sites at different successional stages to infer the consequences of pond management for species via space-for-time substitution (Sayer et al., 2012). Further, the studies undertaken so far have not yet considered the full variety of pond biological groups. It is possible, for example, that some species that favour highly terrestrialised, organically-rich ponds may be negatively affected by pond restoration and subsequent management disturbance (Biggs et al., 1994). There are many species of Chironomidae (Order: Diptera) that can compete well in these terrestrialised pond habitats and these species may be negatively affected by restoring open-water conditions. Chironomids are relatively easy to sample using the 
Chironomid Pupal Exuvial Technique (CPET; Wilson and Ruse, 2005). CPET exploits the easy collection and identification of pupal exuviae discarded by emerging adults and there is a European Standard guidance on sampling and processing chironomid pupal exuviae for ecological assessment (CEN, 2006). The technique has been used to measure the ecological status of a range of lake types (Ruse, 2010). CPET is used to obtain representative samples from rivers, canals and lakes. Its use for small ponds is not known but it could fulfil an understanding of the consequences of pond restoration using a Before-After Control-Impact (BACI) approach for three ponds in Norfolk and also make comparisons between overgrown late-succession ponds and opencanopy early succession ponds in the same study area.

\section{METHODS}

\section{Ponds and sample processing}

Three small ponds ( $<40 \mathrm{~m}$ diameter, depth $<1.5 \mathrm{~m})$ within $0.75 \mathrm{~km}$ of each other near Bodham, North Norfolk $\left(52^{\circ} 54^{\prime} \mathrm{N}, 1^{\circ} 09^{\prime} \mathrm{E}\right)$ were chosen prior to two of them, MYST and SABA, being subjected to major scrub and sediment removal during September and November 2011 (photographs in Sayer et al., 2013). The third pond, RAIL, was left undisturbed as a control. Natural recolonisation of ponds by flora and fauna occurred. Prior to restoration, all three ponds were CPET-sampled monthly from May to September 2010 and April to September 2011. After restoration the ponds were again sampled monthly from March until September 2012 and May to September 2013. Additional sampling was also undertaken in May 2015 to help understand longer term change. Floating chironomid pupal exuviae were collected with a $0.25 \mathrm{~mm}$ mesh net from all accessible parts of these small ponds. When possible, the netted sample was sieved on site to facilitate transport in a $150 \mathrm{~mL}$ pot. Removal of bulky material was achieved by passing the sample through a $4 \mathrm{~mm}$ and a $0.25 \mathrm{~mm}$ mesh sieve, the residue of the coarse sieve was refloated and passed again through the sieve stack before repeating at least once more. At the laboratory all chironomid pupal skins were sorted and identified to species using Langton and Visser (2003). To facilitate a better understanding of chironomid-environment relations in farmland ponds of the region a further nine overgrown farm ponds and two restored ponds near Baconsthorpe, immediately south of the Bodham ponds, were sampled. Sampling the overgrown Baconsthorpe ponds was in preparation for the restoration of five of them by November 2017, leaving four ponds unmanaged as controls. Pupal exuviae samples were taken from these eleven ponds in June and September 2016. Additionally, a single CPET sample was collected in May 2015 from five small, open-canopy, managed farm ponds near Little Dunham, $44 \mathrm{~km}$ to the south-west of Bodham.

Monthly dissolved oxygen, conductivity $\left(25^{\circ} \mathrm{C}\right)$ and pH data were recorded using Hach 1001 Intellical probes and a HQ30d Hach meter, $\mathrm{pH}$ probe set PHC101 was used throughout the monitoring programme so as to reduce error through variation. Error was determined as \pm 0.3 for all probes. Measurements were taken during daylight hours at $10 \mathrm{~cm}$ depth intervals from a boat above the deepest part at the Bodham ponds from April 2010 until September 2011 and then the same regime postrestoration from December 2011 until December 2012 and from February 2013 until September 2013. Baconsthorpe ponds were similarly sampled on ten occasions from August 2010 to April 2017. Mean data for each parameter across the depth strata for each pond were averaged for pre- and post-restoration samples. Maximum depth was recorded on each sampling occasion and averaged for each pond pre- and post-restoration. Alkalinity was recorded over the same periods by filling a $2 \mathrm{~L}$ bottle just below the surface at the deepest part of each pond. Total alkalinity was measured on-site immediately after collection using a Hach test kit, model AL-DT and Hach method 8203. Titration of 1.6N H2SO4 was performed to a single endpoint of $\mathrm{pH} 4.5$ using Bromocresol-green Methyl-red indicator. Total alkalinity was read directly from the apparatus. For nutrient analysis acid-washed $250 \mathrm{~mL}$ Nalgene bottles were used to collect filtered and unfiltered water. Unfiltered water was collected directly from the pond at a depth of $20 \mathrm{~cm}$. Alkalinity and nutrient data were averaged for each Bodham pond pre- and post-restoration and for the other ponds. Water analysis conformed to Patrick et al. (1991). All environmental data were compared with normal probability plots to test for normality by correlation (Ryan and Joiner, 1976) and transformed when necessary. Oxygen, conductivity, alkalinity, $\mathrm{pH}$, maximum depth, total phosphorus (TP), nitrate, soluble reactive phosphorus (SRP) data were all normally-distributed while SRP and chlorophyll $a$ both required $\log _{10}$ transformation.

\section{Data analysis}

Chironomid counts for all Bodham samples taken before September 2011 from the same pond were amalgamated and similarly for all samples taken after the restoration period. Rarefaction was used to compare expected species richness between ponds of the same standard sample size (Hurlbert, 1971). The resulting rarefaction curves provided a graphical comparison of species diversity that accounted for sample size differences. For all other analyses, species counts were recorded as a percentage of the total number of pupal skins collected for the amalgamated samples from each pond. Data for the two 
samples from each of the eleven Baconsthorpe ponds were also amalgamated and expressed as percentages of the total pupal exuviae collected from each pond. Species counts of the single samples from Little Dunham were expressed as percentages. Subsequent analyses were based on square root transformed percentage chironomid data. This transformation was applied to reduce the skewed effects of low species abundances (Fry, 1994). Pairwise, quantitative similarity between all three Bodham ponds, before and after restoration, was compared using the Morisita-Horn index which is not influenced by differences in species richness or sample size (Magurran, 2004). It is sensitive to the abundance of the most common species but square root transformation reduced this.

Spatial representation of species compositional turnover between the six Bodham samples from the three ponds (before and after restoration period) and the eleven Baconsthorpe ponds was achieved using Detrended Correspondence Analysis (DCA; Hill, 1979). The first DCA axis had a gradient length of 5.7 standard deviation units which requires unimodal rather than linear analysis. Direct relationships between chironomid species and environmental data were therefore investigated by unimodal Canonical Correspondence Analysis (CCA) using biplot-scaling with emphasis on inter-species distances. Both DCA and CCA were performed using CANOCO for Windows (Lepš and Šmilauer, 2003). In addition to the environmental data described, a further binary variable of 'Treatment' was included: restored or unrestored. Environmental variables significantly related to species data were selected by forward stepwise regression based on the observed $F$-ratio compared to that obtained by running 999 random permutations of the same data. Probability levels of significance began at $\alpha=0.05$ for selection of the first variable but were then adjusted for Bonferroni inequality with $\mathrm{P}=\alpha / \mathrm{n}$, where $\mathrm{n}$ is the variable rank, this protected against inclusion of redundant variables (Manly, 1991). To explore the compositional differences between all the overgrown and open-canopy ponds, including the BACI ponds, a DCA was applied to the whole chironomid data set. Ponds with three or less species were excluded from ordination analysis to avoid spurious relationships. This resulted in six Baconsthorpe ponds and one pond at Little Dunham being omitted from the DCA.

\section{RESULTS}

A total of 79 species have been collected so far from all ponds surveyed (Tab. 1). Species of pupal exuviae listed without author have been identified from Langton and Visser (2003) but are not currently associated with recognised adult species. Sample size varied widely according to the number of samples taken and whether the pond had been restored. In all three ponds more pupal exuviae were collected after the restoration period than before. Rarefaction curves estimate the number of species that would have been obtained had there been fewer individuals sampled. The expected number of species for smaller samples is obtained from the aggregate total of species abundance from the pond. The expected number of species for the actual number of exuviae collected at a pond before restoration can therefore be compared with the expected number of species for the same number after the restoration period (Fig. 1). Unambiguous significant difference is graphically illustrated between rarefaction curves that do not cross. In all three ponds, species diversity was greater after the restoration period than before. The most notable increases in species diversity were at the restored ponds MYST and SABA compared with the control pond RAIL. The Morisita-Horn index revealed that the highest similarity was between RAIL before September 2011 and RAIL after September 2011 (Tab. 2). However, the similarity of chironomid species abundances between the restored MYST 'after' and SABA 'after' ponds was almost as high. MYST 'before' and SABA 'before' were highly similar to their respective ponds after restoration. The control pond RAIL was least similar to SABA and MYST irrespective of comparing species composition before or after the restoration of the latter ponds. After recolonisation of the restored ponds there were very few chironomid species that were negatively affected by tree and sediment removal. The semi-terrestrial Metriocnemus eurynotus was one of the them. Another species not found after restoration was Cricotopus intersectus which lives on hard surfaces and feeds on detritus and periphyton.

Mean environmental measurements for three Bodham ponds before and after the September 2011 restoration are provided in the online supplement. Mean $\mathrm{pH}$ and dissolved oxygen increased after the restoration period while conductivity, alkalinity and phosphorus all decreased. In a CCA, alkalinity explained $32 \%$ of species distribution across the Bodham and Baconsthorpe sites. Together with dissolved oxygen these were the only significant variables remaining after forward regression $F$-ratios were compared to those of random permutations of the data. Fig. 2 displays the CCA ordering of samples in relation to alkalinity and oxygen. The other vector 'Treatment' was supplementary and had no influence on the ordination. Independently 'Treatment' explained 21\% of species distribution among sites. Species names are omitted for clarity although the numbers accord with species numbered in Tab. 1. Unrestored ponds occupy the right side of the ordination plot. Restored ponds plus the control site RAIL occupy the left side of the CCA plot associated with the lowest alkalinity and the highest 


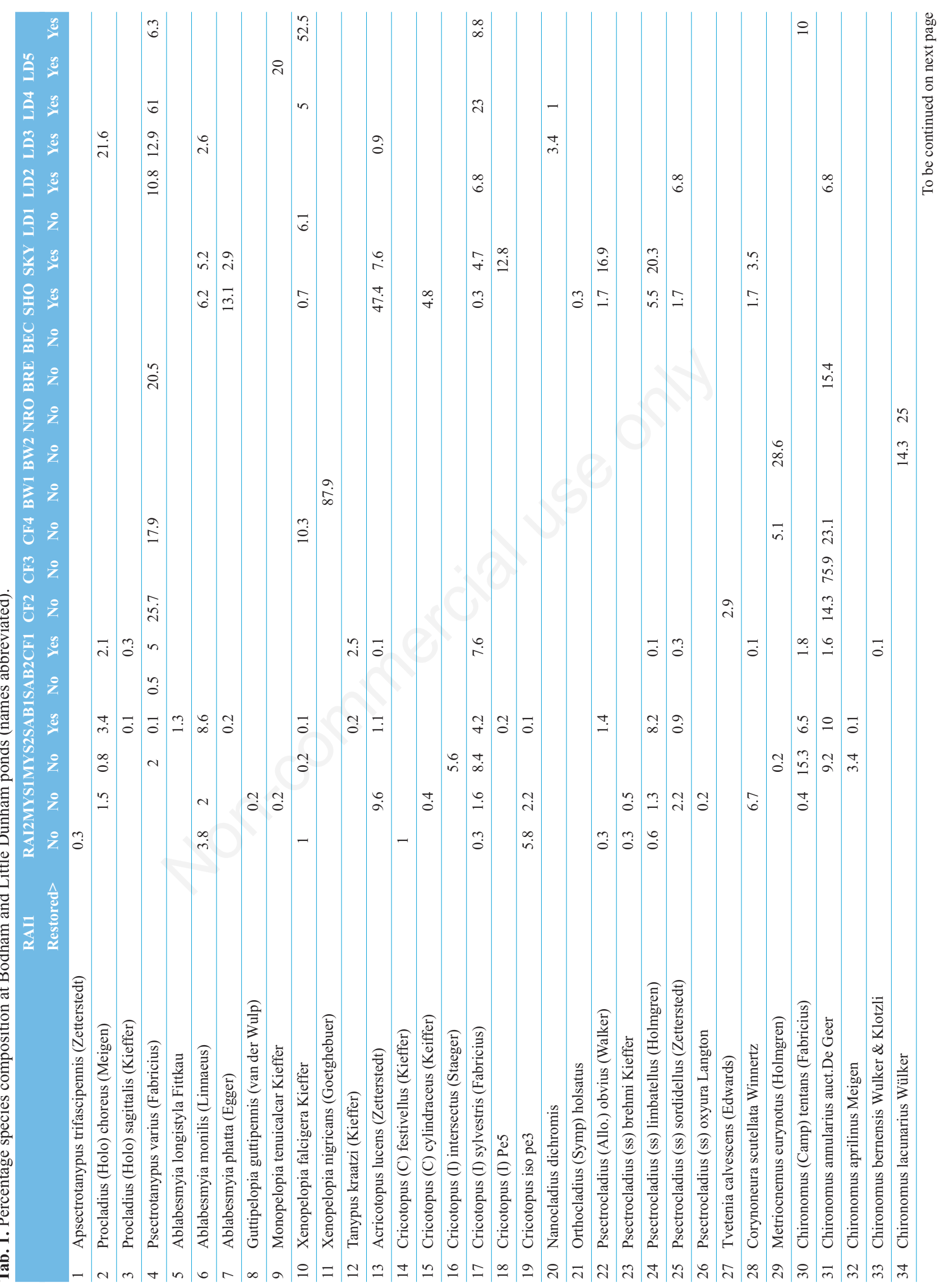




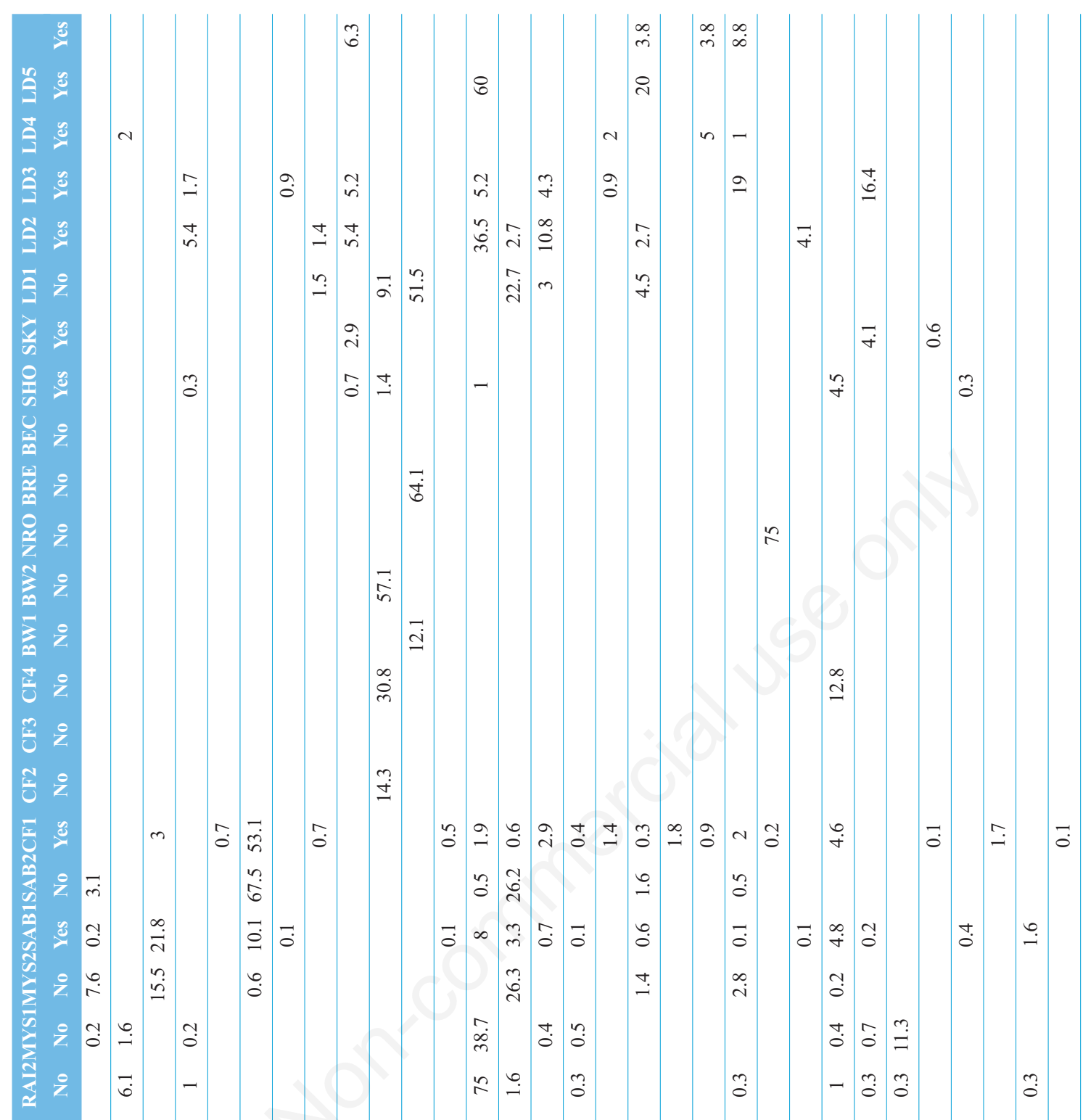

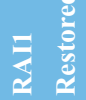

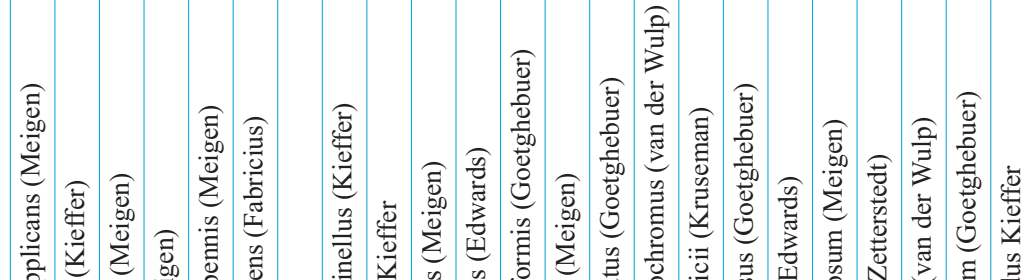

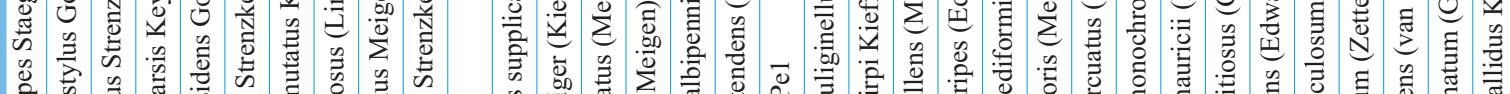

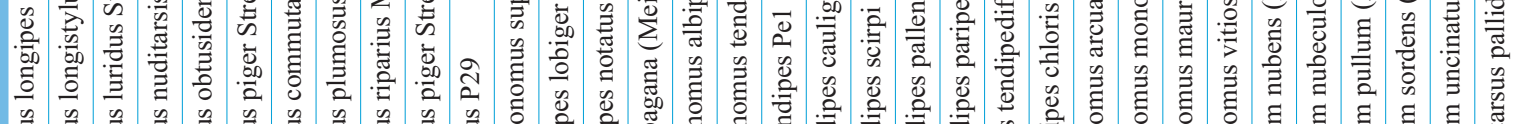

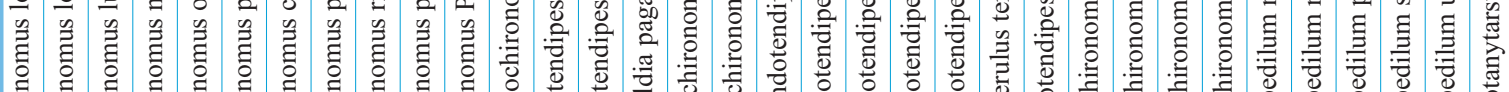

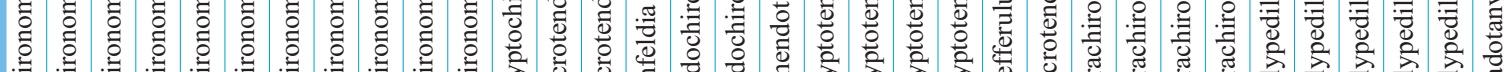

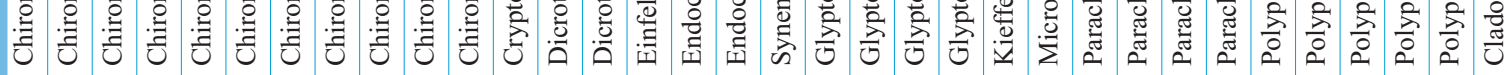

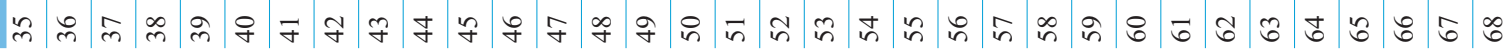




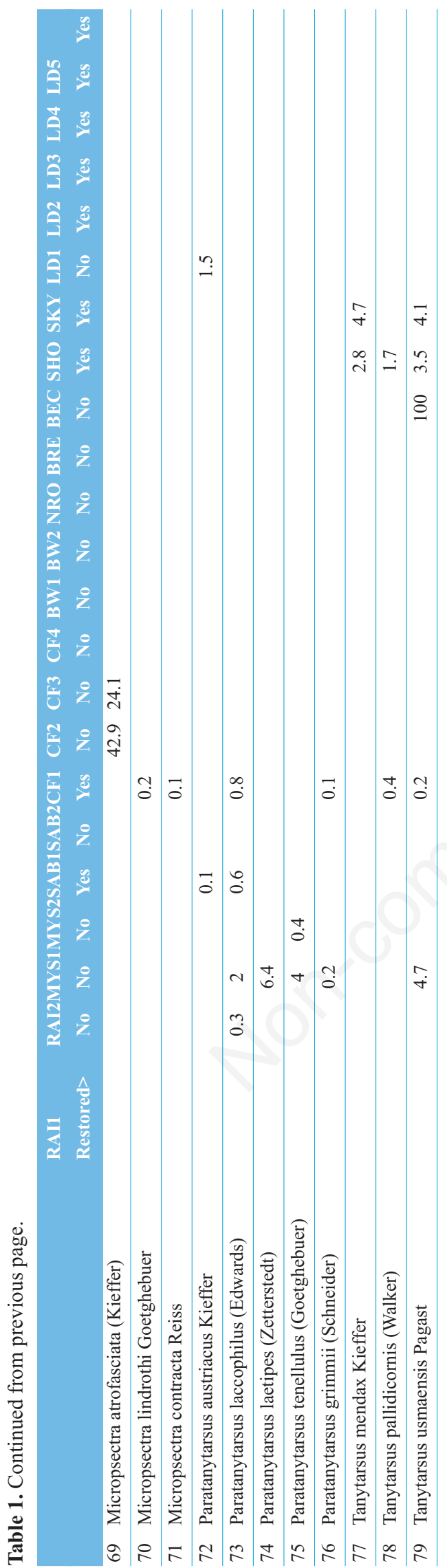

oxygen concentrations as compared with the respective ponds before the restoration period.

The DCA of all ponds sampled for chironomids, after deleting those with less than 4 species, had a first axis gradient length of 5.0 SD units which significantly explained $15.8 \%$ of the species variance. Managed ponds, plus RAIL, occur towards the lower right of the DCA plot (Fig. 3) while the remaining unrestored ponds occur towards the upper left of the plot. Numbered species are fully named in Tab. 1. Species associated with restored

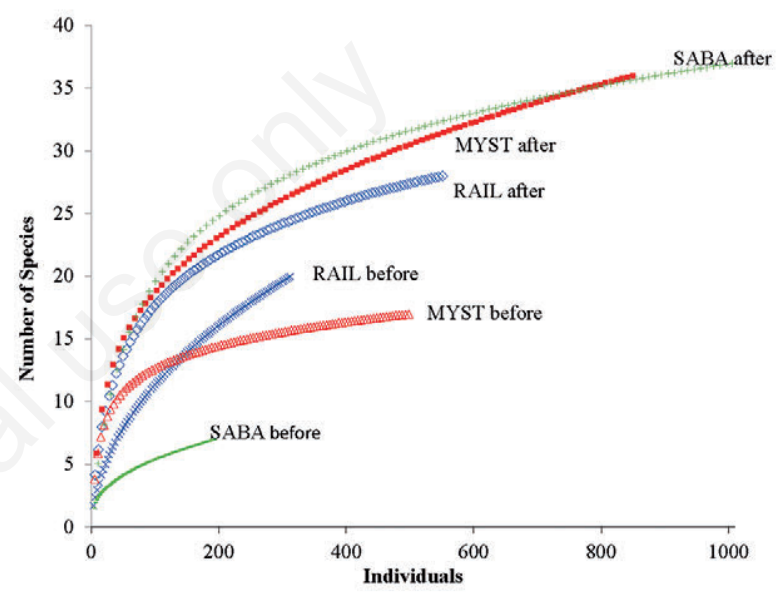

Fig. 1. Estimated species numbers for pupal abundances sampled from Bodham ponds before and after the restoration period.

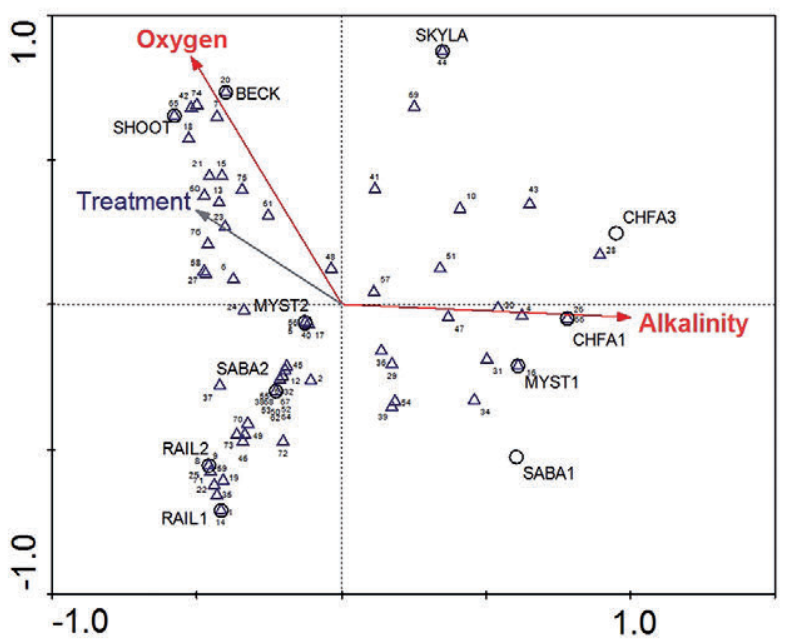

Fig. 2. CCA ordering of Bodham/Baconsthorpe ponds and species constrained by Alkalinity and Oxygen with Treatment as a supplementary variable. Numbered triangles relate to species in Tab.1. Circles depict position of ponds. 
ponds and RAIL included Ablabesmyia monilis, Ablabesmyia phatta, Acricotopus lucens, Psectrocladius (Allopsectrocladius) obvius, Psectrocladius (s.s.) sordidellus, Corynoneura scutellata, Chironomus nuditarsis, Chironomus riparius, Einfeldia pagana, Endochironomus albipennis, Endochironomus tendens, Glyptotendipes scirpi, Parachironomus arcuatus and Paratanytarsus laccophilus. Explanations for why these species could be associated with environmental changes connected to restoring these farm ponds follow in the Discussion section.

\section{DISCUSSION}

This research is at an interim period of the pond restoration programme as five among nine more ponds around Baconsthorpe will be restored. In the original BACI study, the control pond RAIL was richer in species than MYST and SABA before their restoration but both restored ponds exceeded RAIL in species numbers following restoration. In all three ponds the rarefaction curves confirmed that in each case species diversity was significantly greater after the restoration period than before. Chironomid species composition at each of the three ponds was highly similar before and after September 2011, however, the restored ponds had an even greater similarity between them than with their own unrestored state. This is in contrast to the control pond which changed little because it was left undisturbed. Few species were negatively affected by tree and sediment removal once recolonisation had occurred. Similarity of chironomid assemblages, before and after restoration, remained high. Predation could be a further influence on

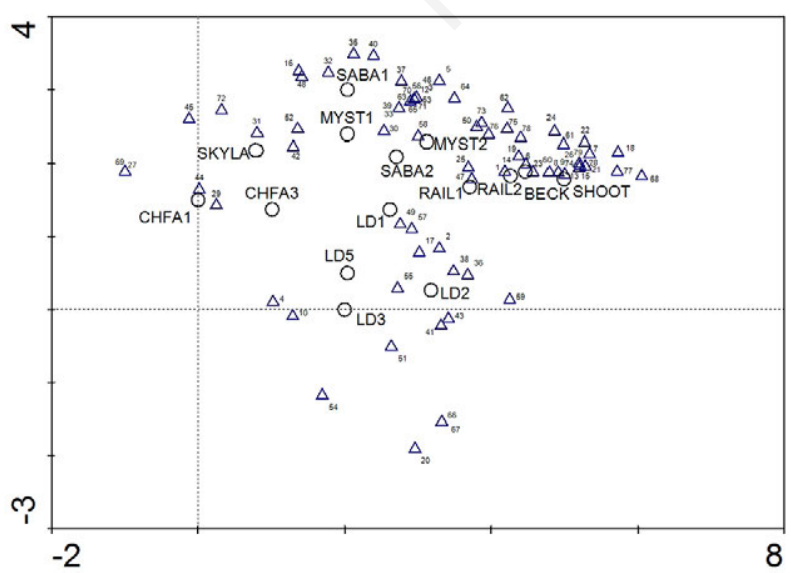

Fig. 3. DCA of Bodham/Baconsthorpe and Little Dunham ponds. Numbered triangles relate to species in Tab.1. Circles depict position of ponds. Axes in Standard Deviation units. chironomids. Only RAIL had fish throughout the chironomid study, however, there has been no assessment of the predatory effects of fish or macroinvertebrates in these ponds. Restoration of the Norfolk ponds has significantly increased chironomid species richness. Gioria et al. (2010) researching farmland pond conservation found models of plant and beetle species richness required a lower number of predicting abiotic variables compared to models of species composition, both plants and beetles were good surrogate indicators for the pond community. Similarly, the trophic and biotic interactions of chironomids within the pond community make them appropriate surrogates to monitor pond restoration.

When species compositional turnover was investigated by CCA across all the Bodham and Baconsthorpe ponds, unmanaged and restored, both RAIL 1 and 2 were positioned among the restored ponds. This was also still evident when the managed Little Dunham ponds were included in a DCA. Alkalinity, conductivity and phosphorus decreased following restoration in September 2011, even at RAIL. It is not known whether there had been a significant increase in rainfall or other influence since September 2011. Shading by trees at RAIL was estimated as $10 \%$ cover which is equivalent to the shading at MYST and SABA after their restoration. All three ponds experienced increased $\mathrm{pH}$ and dissolved oxygen after restoration of MYST and SABA. This would be expected with daytime measurements where submerged plant growth had increased. During daylight photosynthesis there would be a net removal of carbon dioxide with a consequent reduction in carbonic acid and an increased $\mathrm{pH}$ (Talling, 2010).

Based on DCA and CCA ordinations, chironomid species composition at RAIL is more closely related to open-canopy ponds than to other unrestored ponds in this study. The greater openness of RAIL compared to other unrestored ponds permitted greater plant growth. Some of the species associated with the restored ponds of Bodham, Baconsthorpe, Little Dunham and RAIL are discussed here. Comments on species feeding and habitat preferences are largely drawn from the senior

Tab. 2. Morisita-Horn \%Similarity. Highest similarities in bold.

\begin{tabular}{lccccc} 
& MYST1 & SABA1 & RAIL2 & MYST2 & SABA2 \\
RAIL1 & 9.7 & 12.1 & $\mathbf{6 4 . 7}$ & 36.9 & 16.8 \\
\hline MYST1 & & & 9.9 & $\mathbf{6 0 . 0}$ & 41.0 \\
\hline SABA1 & & 3.9 & 28.2 & $\mathbf{5 0 . 3}$ \\
\hline RAIL2 & & & 40.2 & 22.8 \\
\hline MYST2 & & & & $\mathbf{6 3 . 7}$
\end{tabular}

1, before; 2, after restoration period. 
author's own research, Langton and Visser (2003), Vallenduuk and Moller Pillot (2007), Moller Pillot (2009, 2013). Ablabesmyia phatta is associated with submerged plants, which increased considerably following scrub clearance. Acricotopus lucens is also found living on plants, feeding on diatoms and other periphyton. Psectrocladius obvius is another algal feeder. Psectrocladius sordidellus lives on hard surfaces such as plants and stones. Corynoneura scutellata is a plant-dwelling algal grazer. Chironomus nuditarsis is a silt-dweller tolerant of anoxia. Chironomus riparius is a mud-eater with typically 4-7 generations making it a suitable early coloniser of freshly-dug pond habitats. Einfeldia pagana is a univoltine, surface-scraper tolerant of low oxygen conditions. Endochironomus albipennis, Endochironomus tendens and Glyptotendipes scirpi are all leaf-miners which spin nets to filter feed. Parachironomus arcuatus is a plant-dweller, algal/detritus feeder and facultative predator. Paratanytarsus laccophilus is typically found in ponds and is usually parthenogenetic and suitable for rapid colonisation of fresh habitats. This study indicates that removing trees and scraping-out the top sediments provided a tabula rasa for natural colonisation by chironomids. Céréghino et al. (2008) found that vegetation differences between ponds resulting from different levels of human intervention played a role in selecting invertebrate species traits. At these Norfolk ponds earliest colonisation was by mud-eating species with rapid colonisation traits such as parthenogenesis, multiple generations in one year and tolerance of low oxygen conditions. After opening up the canopy the subsequent plant growth improved oxygenation and habitat structure so that species dependent on these conditions were then able to compete with the early colonisers. Further testing of the theory that species richness increases after restoring overgrown farm ponds will be possible now that five more ponds have been restored while four among them remain undisturbed as controls. It will also be instructive to monitor how species richness and composition in restored ponds changes with time.

\section{CONCLUSIONS}

Restoration of the Norfolk ponds resulted in a significant increase of chironomid species. High similarity was retained between chironomid assemblages before and after the restoration period. Few species disappeared after restoration once recolonisation over three years had elapsed. Restoring an open canopy led to a more complex habitat structure and wider physicochemical variation. This correlated with colonisation by additional species adapted to the novel conditions provided by restoration.

\section{REFERENCES}

Alderton E, Sayer C, Davies R, Lambert S, Axmacher J, 2017. Buried alive: Aquatic plants survive in 'ghost ponds' under agricultural fields. Biol. Conserv. 212:105-110.

Biggs J, Corfield A, Walker D, Whitfield M, Williams P, 1994. New approaches to the management of ponds. British Wildlife 5:273-287.

CEN, 2006. Water Quality - Guidance on sampling and processing of the pupal exuviae of Chironomidae for ecological assessment. European Committee for Standardization, Standard EN15196, Brussels: 9 pp.

Céréghino R, Ruggiero A, Marty P, Angélibert S, 2008. Influence of vegetation cover on the biological traits of pond invertebrate communities. Ann. Limnol.-Int. J. Lim. 44:267-274.

Davies SR, Sayer CD, Greaves H, Siriwardena GM, Axmacher JC, 2016. A new role for pond management in farmland bird conservation. Agr. Ecosyst. Environ. 233:179-191.

Fry JC, 1994. Biological data analysis. Oxford University Press, Oxford: $418 \mathrm{pp}$.

Gioria M, Bacaro G, Feehan J, 2010. Identifying the drivers of pond biodiversity: the agony of model selection. Community Ecol. 11:179-186.

Hill MO, 1979. DECORANA - a FORTRAN program for detrended correspondence analysis and reciprocal averaging. Ecology and System, Cornell University, New York: 30 pp.

Hurlbert SH, 1971. The non-concept of species diversity: a critique and alternative parameters. Ecology 52:577-586.

Langton PH, Visser H, 2003. Chironomid exuviae. A key to pupal exuviae of the West Palaearctic Region. CD-ROM produced by ETI, University of Amsterdam.

Lepš J, Šmilauer P, 2003. Multivariate analysis of ecological data using CANOCO. Cambridge University Press, Cambridge: 269 pp.

Magurran AE, 2004. Measuring biological diversity. Blackwell Publishing, Oxford: 256 pp.

Manly BFJ, 1991. Randomization and Monte Carlo methods in biology. Chapman and Hall, London: 281 pp.

Moller Pillot HKM, 2009. Chironomidae larvae: Biology and ecology of the Chironomini. KNNV Publishing, Zeist: 270 pp.

Moller Pillot HKM, 2013. Chironomidae larvae: Biology and ecology of the aquatic Orthocladiinae. KNNV Publishing, Zeist: $312 \mathrm{pp}$.

Patrick ST, Juggins S, Waters D, Jenkins A, 1991. The United Kingdom Acid Waters Monitoring Netwrok: site descriptions and methodology report, ENSIS, London.

Ruggiero A, Céréghino R, Figuerola J, Marty P, Angélibert S, 2008. Farm ponds make a contribution to the biodiversity of aquatic insects in a French agricultural landscape. C. R. Biol. 331:298-308.

Ruse LP, 2010. Classification of nutrient impact on lakes using the chironomid pupal exuvial technique. Ecol. Indic. 10:594-601.

Ryan TA, Joiner BL, 1976. Normal probability plots and tests for normality. Technical Report. Statistics Department, Pennsylvania State University: 19 pp.

Sayer C, Andrews K, Shilland E, Edmonds N, Edmonds -Brown R, Patmore I, Emson D, Axmacher J, 2012. The role of pond management for biodiversity conservation in an agricultural landscape. Aquat. Conserv. 22:626-638.

Sayer C, Shilland E, Greaves H, Dawson B, Patmore I, Emson 
D, Alderton E, Robinson R, Andrews K, Axmacher J, Wiik E, 2013. Managing Britain's ponds - conservation lessons from a Norfolk farm. British Wildlife 25:21-28.

Talling JF, 2010. $\mathrm{pH}$, the $\mathrm{CO}_{2}$ system and freshwater science. Freshw. Rev. 3:133-146.

Vallenduuk HJ, Moller Pillot HKM, 2007. Chironomidae larvae: General ecology and Tanypodinae. KNNV Publishing, Zeist: 144 pp.
Wilson RS, Ruse LP, 2005. A guide to the identification of genera of chironomid pupal exuviae occurring in Britain and Ireland and their use in monitoring lotic and lentic freshwaters. FBA Special Publication no. 13. Freshwater Biological Association, Ambleside: 176 pp.

Wood PJ, Greenwood MT, Agnew MD, 2003. Pond biodiversity and habitat loss in the UK. Area 35:206-216. 